\title{
Astrocyte metabolism of the medium-chain fatty acids octanoic acid and decanoic acid promotes GABA synthesis in neurons via elevated glutamine supply
}

Jens V. Andersen ${ }^{* *}$, Emil W. Westi ${ }^{1}$, Emil Jakobsen ${ }^{1}$, Nerea Urruticoechea ${ }^{1}$, Karin Borges ${ }^{2}$ and Blanca I. Aldana ${ }^{1 *}$ (1)

\begin{abstract}
The medium-chain fatty acids octanoic acid (C8) and decanoic acid (C10) are gaining attention as beneficial brain fuels in several neurological disorders. The protective effects of C8 and C10 have been proposed to be driven by hepatic production of ketone bodies. However, plasma ketone levels correlates poorly with the cerebral effects of C8 and $\mathrm{C10}$, suggesting that additional mechanism are in place. Here we investigated cellular C8 and C10 metabolism in the brain and explored how the protective effects of C 8 and C10 may be linked to cellular metabolism. Using dynamic isotope labeling, with $\left[\mathrm{U}-{ }^{13} \mathrm{C}\right] \mathrm{C} 8$ and $\left[\mathrm{U}-{ }^{13} \mathrm{C}\right] \mathrm{C} 10$ as metabolic substrates, we show that both $\mathrm{C} 8$ and $\mathrm{C} 10$ are oxidatively metabolized in mouse brain slices. The ${ }^{13} \mathrm{C}$ enrichment from metabolism of $\left[\mathrm{U}-{ }^{13} \mathrm{C}\right] \mathrm{C} 8$ and $\left[\mathrm{U}-{ }^{13} \mathrm{C}\right] \mathrm{C} 10$ was particularly prominent in glutamine, suggesting that $\mathrm{C} 8$ and $\mathrm{C} 10$ metabolism primarily occurs in astrocytes. This finding was corroborated in cultured astrocytes in which C8 increased the respiration linked to ATP production, whereas C10 elevated the mitochondrial proton leak. When $\mathrm{C} 8$ and $\mathrm{C} 10$ were provided together as metabolic substrates in brain slices, metabolism of $\mathrm{C} 10$ was predominant over that of $\mathrm{C} 8$. Furthermore, metabolism of both $\left[\mathrm{U}-{ }^{13} \mathrm{C}\right] \mathrm{C} 8$ and $\left[\mathrm{U}-{ }^{13} \mathrm{C}\right]$ C10 was unaffected by etomoxir indicating that it is independent of carnitine palmitoyltransferase I (CPT-1). Finally, we show that inhibition of glutamine synthesis selectively reduced ${ }^{13} \mathrm{C}$ accumulation in GABA from $\left[U-{ }^{13} \mathrm{C}\right] \mathrm{C} 8$ and $\left[\mathrm{U}-{ }^{13} \mathrm{C}\right]$ C10 metabolism in brain slices, demonstrating that the glutamine generated from astrocyte C 8 and C10 metabolism is utilized for neuronal GABA synthesis. Collectively, the results show that cerebral C8 and C10 metabolism is linked to the metabolic coupling of neurons and astrocytes, which may serve as a protective metabolic mechanism of C 8 and C10 supplementation in neurological disorders.
\end{abstract}

Keywords: MCT, MCFA, Neurotransmitter recycling, Mitochondria, $\beta$-hydroxybutyrate, Caprylic acid (C8), Capric acid (C10)

*Correspondence: jens.andersen@sund.ku.dk; blanca.aldana@sund.ku.dk ${ }^{1}$ Department of Drug Design and Pharmacology, Faculty of Health and Medical Sciences, University of Copenhagen, Universitetsparken 2, 2100 Copenhagen E, Denmark

Full list of author information is available at the end of the article

\section{Introduction}

Glucose is the primary fuel of the brain. However, brain cells can utilize several other metabolic substrates including amino acids, ketone bodies and fatty acids [1]. Medium-chain fatty acids (MCFAs) are gaining attention as brain fuels [2-4]. Diets enriched with mediumchain triglycerides (MCTs) of octanoic acid (C8) and decanoic acid (C10) have shown beneficial effects in 
neurodegenerative diseases [5]. In patients with mild cognitive impairment and Alzheimer's disease, supplementation of $\mathrm{C} 8$ and $\mathrm{C} 10$ has been shown to improve both cognition and brain energy metabolism [6-8]. Furthermore, MCT supplementation appears to be efficient in the management of drug-resistant epilepsy [9-11]. Ketone body production driven by hepatic metabolism of $\mathrm{C} 8$ and $\mathrm{C} 10$ has been suggested to be the main mechanism underlying the anti-epileptic effects of the MCT diet [9]. However, studies have found poor correlation between seizure control and plasma ketone levels [12, 13]. Both $C 8$ and $C 10$ are able to cross the blood brain barrier $[14,15]$ and can reach cerebral concentrations of $200 \mu \mathrm{M}$ in mice after enriched feeding [16, 17]. As $\mathrm{C} 8$ and $\mathrm{C} 10$ are well-known metabolic substrates in the periphery [2], they may serve specific metabolic purposes in the brain as well.

Neurons and astrocytes function in close metabolic collaboration [18]. The energy metabolism of neurons and astrocytes is closely linked to both synthesis and metabolism of glutamate and GABA, being the primary excitatory and inhibitory neurotransmitters of the brain, respectively $[19,20]$. Astrocytes take up a large fraction of the released glutamate and GABA from the synapse, and in turn, provide neurons with glutamine, which is an essential substrate for re-synthesis of glutamate and GABA in the neurons [21, 22]. Inadequate astrocyte glutamine synthesis has been reported in multiple diseases, including epilepsy, and experimental inhibition of glutamine synthesis leads to seizures [23-25]. Glutamine is exclusively synthesized in astrocytes from glutamate catalyzed by the enzyme glutamine synthetase (GS) [26]. This process is closely linked to cellular energy metabolism as the tricarboxylic acid (TCA) cycle intermediate $\alpha$-ketoglutarate serves as the precursor of glutamate synthesis and hereby also glutamine synthesis in astrocytes [27]. In the mitochondria, $\mathrm{C} 8$ and $\mathrm{C} 10$ are converted by $\beta$-oxidation into acetylCoA units, which can enter the TCA cycle and hereby support cellular metabolism. Previous studies have suggested that astrocytes may be the main metabolic compartment for $\mathrm{C} 8$ metabolism in the brain [28-30]. However, brain metabolism of C8 and C10 and how this may be linked to neurotransmitter recycling, has not been explored in detail.

The aim of this study was therefore to provide a better understanding of cellular $\mathrm{C} 8$ and $\mathrm{C} 10$ metabolism in the brain. To achieve this we mapped $\mathrm{C} 8$ and $\mathrm{C} 10$ metabolism in acutely isolated cerebral cortical slices by using ${ }^{13} \mathrm{C}$ isotopically enriched $\mathrm{C} 8$ and $\mathrm{C} 10$ with subsequent gas chromatography-mass spectrometry (GC-MS) analysis. We also conducted metabolic competition assays between $\mathrm{C} 8$ and $\mathrm{C} 10$ and investigated the effects of carnitine palmitoyltransferase I (CPT-1) and GS inhibition.
Furthermore, we examined the effect of $\mathrm{C} 8$ and $\mathrm{C} 10$ supplementation on mitochondrial bioenergetics in cultured astrocytes. We provide evidence that both $\mathrm{C} 8$ and $\mathrm{C} 10$ are oxidatively metabolized in brain slices particularly promoting astrocyte glutamine synthesis. Notably, we demonstrate that the glutamine generated by $\mathrm{C} 8$ and C10 metabolism in astrocytes is utilized in neurons for GABA synthesis. Our results provide new insight into $\mathrm{C} 8$ and $\mathrm{C} 10$ metabolism in the brain and potential metabolic mechanisms of MCFA supplementation in different pathologies.

\section{Methods \\ Materials}

The stable ${ }^{13} \mathrm{C}$ enriched compounds $\left[\mathrm{U}_{-}{ }^{13} \mathrm{C}\right]$ octanoic acid ([U- $\left.{ }^{13} \mathrm{C}\right] \mathrm{C} 8$, CLM-3981-PK, 98\%), [U- $\left.{ }^{13} \mathrm{C}\right]$ decanoic acid $\left(\left[\mathrm{U}-{ }^{13} \mathrm{C}\right] \mathrm{C} 10, \mathrm{CLM}-9950-\mathrm{PK}, 98 \%\right)$ and $\left[\mathrm{U}-{ }^{13} \mathrm{C}\right]$ $\beta$-hydroxybutyrate ( $\left[\mathrm{U}_{-}{ }^{13} \mathrm{C}\right] \beta \mathrm{HB}, \mathrm{CLM}-3853-\mathrm{PK}$, sodium salt, 97\%) were all from Cambridge Isotope Laboratories (Tewksbury, USA). Octanoic acid $\left({ }^{12} \mathrm{C} 8, \mathrm{C} 2875\right)$, decanoic acid $\left({ }^{12} \mathrm{C} 10, \mathrm{C} 1875\right),(R)$ - $\beta$-hydroxybutyrate $\left({ }^{12} \mathrm{C}\right.$ $\beta \mathrm{HB}, 54920)$ oligomycin A (75351), carbonyl cyanide 4-(trifluoromethoxy)phenylhydrazone (FCCP, C2920), antimycin A (A8674) rotenone (R8875), (+)-etomoxir (E1905, sodium salt) and L-methionine sulfoximine (MSO, M5379) were from Sigma-Aldrich (St. Louis, MO, USA). All other chemicals used were of the purest grade available from regular commercial sources.

\section{Animals}

Male NMRI mice (Envigo, Cambridgeshire, United Kingdom) of 12 weeks of age (weight: $40.5 \pm 0.5 \mathrm{~g}$ ) were housed in a pathogen-free, temperature and humidity controlled environment at the Department of Drug Design and Pharmacology, University of Copenhagen. The mice were acclimatized for two weeks before experiments and were single-housed in individually ventilated cages with free access to chow and water.

\section{Brain slice incubations}

Incubation of acutely isolated cerebral cortical mouse brain slices were performed as previously described [31], with slight modifications. Briefly, a mouse was euthanized by cervical dislocation and decapitated. The brain was transferred to ice-cold artificial cerebrospinal fluid (ACSF) containing in mM: $\mathrm{NaCl} 128, \mathrm{NaHCO}_{3}$ 25, D-glucose 10, $\mathrm{KCl} 3, \mathrm{CaCl}_{2} 2, \mathrm{MgSO}_{4} 1.2, \mathrm{KH}_{2} \mathrm{PO}_{4}$ $0.4, \mathrm{pH}=7.4$. The cerebral cortex was dissected and sliced $(350 \mu \mathrm{m})$ using a Mcllwain tissue chopper (The Vibratome Company, O'Fallon, MO, USA). The cerebral cortical slices were kept just below the surface of $10 \mathrm{~mL} 37{ }^{\circ} \mathrm{C}$ oxygenated $\left(5 \% \mathrm{CO}_{2} / 95 \% \mathrm{O}_{2}\right)$ ACSF and pre-incubated for $60 \mathrm{~min}$. Subsequently, the media were 
exchanged for ACSF containing the stable ${ }^{13} \mathrm{C}$ enriched compounds $(12 \mathrm{~mL}$ in glass tubes to avoid fatty acid adherence to plastic) supplemented with $5 \mathrm{mM}$ unlabeled D-glucose and incubated for additional $60 \mathrm{~min}$. Two round of slices incubation experiments were performed. In the first round, a competition assay was performed in which the slices were incubated in the presence of either $\left[\mathrm{U}_{-}{ }^{13} \mathrm{C}\right] \mathrm{C} 8,\left[\mathrm{U}_{-}{ }^{13} \mathrm{C}\right] \mathrm{C} 10$ or $\left[\mathrm{U}_{-}{ }^{13} \mathrm{C}\right]$ $\beta \mathrm{HB}$ (all $200 \mu \mathrm{M}) \pm$ competing unlabeled ${ }^{12} \mathrm{C}$ substrates: ${ }^{12} \mathrm{C} 8,{ }^{12} \mathrm{C} 10$ or ${ }^{12} \mathrm{C}-\beta \mathrm{HB}$ (also $\left.200 \mu \mathrm{M}\right)$. Media contain- metabolites of interest. Metabolism of ${ }^{13} \mathrm{C}$ enriched substrates can give rise to complex labeling patterns with multiple ${ }^{13} \mathrm{C}$ isotopologues which are metabolites differing in their ${ }^{13} \mathrm{C}$ composition (denoted as $\mathrm{M}+\mathrm{X}$, where $\mathrm{M}$ is the molecular ion of the metabolite and $\mathrm{X}$ is the number is ${ }^{13} \mathrm{C}$ atoms) as described in [34]. Here data is presented as the molecular carbon labeling (MCL), which is the weighted average of all the different isotopologues of a metabolite [35]. The MCL thus provides a measurement of the overall ${ }^{13} \mathrm{C}$ accumulation in a given metabolite and is calculated as:

$$
\text { Molecular carbon labeling }(M C L)=\frac{(M+1 * 1)+(M+2 * 2)+(M+3 * 3) \ldots(M+X * X)}{\text { Total number of carbon atoms in molecule }}
$$

ing $\mathrm{C} 10\left({ }^{12} \mathrm{C} /{ }^{13} \mathrm{C}\right)$ was prepared directly in ACSF at a final concentration of $200 \mu \mathrm{M}$, whereas $\mathrm{C} 8\left({ }^{12} \mathrm{C} /{ }^{13} \mathrm{C}\right)$ and $\beta \mathrm{HB}\left({ }^{12} \mathrm{C} /{ }^{13} \mathrm{C}\right)$ were prepared as $20 \mathrm{mM}$ stocks. $\mathrm{C} 8 / \mathrm{C} 10$ at concentrations of $200 \mu \mathrm{M}$ have previously been found sufficient to support cellular metabolism [32], and further allows dissolution without the addition of aprotic solvents e.g. dimethylsulfoximide (DMSO) which impairs cellular metabolism [33]. In the second round, the effects of the two metabolic inhibitors etomoxir (stock: $5 \mathrm{mM}$, final concentration: $100 \mu \mathrm{M}$ ) and MSO (stock: $200 \mathrm{mM}$, final concentration: $5 \mathrm{mM}$ ) were investigated. To ensure efficient inhibition, prior to the addition of the ${ }^{13} \mathrm{C}$ enriched substrates, the inhibitors were applied after 30 min of pre-incubation and also throughout the entire incubation period. All incubations were terminated by transferring slices into ice-cold $70 \%$ ethanol. The slices were sonicated and centrifuged $(4000 g \times 20 \mathrm{~min})$ and the supernatant was removed and lyophilized before GC-MS or HPLC analysis. Pellets were saved for protein determination by Pierce protein assay.

\section{Metabolic mapping using gas chromatography-mass spectrometry (GC-MS) analysis}

$\left[\mathrm{U}_{-}{ }^{13} \mathrm{C}\right] \mathrm{C} 8,\left[\mathrm{U}_{-}{ }^{13} \mathrm{C}\right] \mathrm{C} 10$ and $\left[\mathrm{U}_{-}{ }^{13} \mathrm{C}\right] \beta \mathrm{HB}$ will all enter cellular metabolism as ${ }^{13} \mathrm{C}$ enriched acetylCoA, which will lead to ${ }^{13} \mathrm{C}$ enrichment of TCA cycle intermediates and connected amino acids. The metabolite ${ }^{13} \mathrm{C}$ enrichment from metabolism of $\left[\mathrm{U}_{-}{ }^{13} \mathrm{C}\right] \mathrm{C} 8,\left[\mathrm{U}_{-}{ }^{13} \mathrm{C}\right] \mathrm{C} 10$ and $\left[\mathrm{U}_{-}{ }^{13} \mathrm{C}\right]$ $\beta \mathrm{HB}$ was determined by $\mathrm{GC}-\mathrm{MS}$ analyses as previously described [34]. Briefly, slice extracts were reconstituted in water, acidified, extracted twice with ethanol and the metabolites were derivatized using $N$-tert-butyldimethylsilyl- $N$-methyltrifluoroacetamide. Samples were analyzed by GC (Agilent Technologies, 7820A, J\&W GC column HP-5 MS) coupled to MS (Agilent Technologies, 5977E). The isotopic enrichment was corrected for the natural abundance of ${ }^{13} \mathrm{C}$ by analyzing standards of the unlabeled

\section{Determination of amino acid amounts}

\section{by high-performance liquid chromatography (HPLC) analysis}

Aqueous extracts of the brain slices were analyzed by reverse-phase HPLC (Agilent Technologies, 1260 Inifinity, Agilent ZORBAX Eclipse Plus C18 column) to quantitatively determine the amounts of the following amino acids: aspartate, glutamate, glutamine, taurine \& GABA [36]. A pre-column derivatization with o-phthalaldehyde and fluorescent detection, $\lambda_{\mathrm{ex}}=338 \mathrm{~nm}, \lambda_{\mathrm{em}}=390 \mathrm{~nm}$, was performed. Gradient elution with mobile phase $\mathrm{A}$ (10 $\mathrm{mM} \mathrm{NaH}_{2} \mathrm{PO}_{4}, 10 \mathrm{mM} \mathrm{Na}_{2} \mathrm{~B}_{4} \mathrm{O}_{7}, 0.5 \mathrm{mM} \mathrm{NaN}_{3}, \mathrm{pH}$ 8.2) and mobile phase $\mathrm{B}$ (acetonitrile $45 \%$ : methanol $45 \%$ : $\mathrm{H}_{2} \mathrm{O} 10 \%, \mathrm{~V}: \mathrm{V}: \mathrm{V}$ ) was performed. The amounts of amino acids were determined from analysis of standards of the amino acids of interest. The amino acid amounts of the slice extracts were adjusted to the protein amounts of the slices and are presented as $\mathrm{nmol} / \mathrm{mg}$ protein.

\section{Primary cultures of cortical astrocytes and determination of oxygen consumption rate (OCR)}

Primary cultures of cortical astrocytes were prepared from 7-day-old NMRI mouse pups as previously described [34]. Each plate of cortical astrocytes were prepared from individual batches of pups. Briefly, pups were decapitated and the cerebral cortex excised. The tissue was processed by passage through a $80 \mu \mathrm{m}$ pore size nylon mesh and submersed in a modified Dulbecco's Modified Eagle's Medium (DMEM) supplemented with $2.5 \mathrm{mM}$ L-glutamine, $6 \mathrm{mM}$ glucose, 100,000 i.u. penicillin, $0.04 \mathrm{mM}$ phenol red, $26.2 \mathrm{mM} \mathrm{NaHCO}_{3}$ and $20 \%(\mathrm{v} / \mathrm{v})$ fetal bovine serum. A steel cannula fitted to a syringe was used to dissociate the cells by trituration. The cell suspension was plated in Seahorse XFe96well culture plates and cultured for 21 days at $37^{\circ} \mathrm{C}$ in a humidified atmosphere of $5 \% \mathrm{CO}_{2} / 95 \%$ air. Medium was exchanged twice a week and serum concentration 
reduced to $15 \%$ in the second week and $10 \%$ in the third week and $0.25 \mathrm{mM}$ dibutyryl-cAMP (final concentration) was added to the medium for the last week of culture. The oxygen consumption rate (OCR) of the cultured astrocytes were determined using a Seahorse XFe96 analyzer as previously described [37]. Briefly, the astrocytes were washed twice and the media changed to Seahorse assay medium (DMEM with $2.5 \mathrm{mM}$ glucose and $3 \mathrm{mg} / \mathrm{L}$ phenol red, $\mathrm{pH}$ 7.4) and kept at $37{ }^{\circ} \mathrm{C}$ (non- $\mathrm{CO}_{2}$ incubator) for $1 \mathrm{~h}$. When indicated the assay medium was further supplemented with $\mathrm{C} 8, \mathrm{C} 10$ or the combination (all $200 \mu \mathrm{M})$. As for the brain slice incubations, media containing $\mathrm{C} 10$ was prepared directly in Seahorse assay medium at a final concentration of $200 \mu \mathrm{M}$, whereas $\mathrm{C} 8$ was prepared as a $20 \mathrm{mM}$ stock. In total, 12 measurement cycles ( 2 min mix, 1 min wait, 3 min measure) were performed (as outlined in Fig. 2B). After 3 initial baseline measurements, 3 injections were performed (all final concentrations): (1) $1.0 \mu \mathrm{M}$ oligomycin A, (2) $0.5 \mu \mathrm{M}$ FCCP, (3) $0.5 \mu \mathrm{M}$ antimycin A and $0.5 \mu \mathrm{M}$ rotenone. After each injection 3 measurement cycles were performed. The non-mitochondrial OCR was subtracted from all data points (Fig. 2B). To account for potential inter-well variability during the culturing period, data is presented as OCR as \% of control (glucose condition).

\section{Experimental design and statistical analyses}

Data is presented as means \pm standard error of the mean (SEM), with individual data points presented. Each data point (represented by circles in the graphs) represents biological replicates (i.e. from individual animals), which is denoted by ' $n$ ' in the figure legends. Statistical analyses were performed by repeated measurements 1-way ANOVA with Bonferroni correction for multiple comparisons. The significance level was set at $\mathrm{p}<0.05$ and is indicated with a single asterisk.

\section{Results \\ Oxidative C8 and C10 metabolism promotes astrocyte glutamine synthesis in brain slices}

To get an overview of the extent and possible compartmentation of $\mathrm{C} 8$ and $\mathrm{C} 10$ brain metabolism, we first incubated acutely isolated cerebral cortical slices in the presence of either $\left[\mathrm{U}_{-}{ }^{13} \mathrm{C}\right] \mathrm{C} 8$ or $\left[\mathrm{U}_{-}{ }^{13} \mathrm{C}\right] \mathrm{C} 10$ (Fig. 1). $\left[\mathrm{U}_{-}{ }^{13} \mathrm{C}\right] \mathrm{C} 8$ and $\left[\mathrm{U}_{-}{ }^{13} \mathrm{C}\right] \mathrm{C} 10$ will enter cellular metabolism as ${ }^{13} \mathrm{C}$ enriched acetylCoA units and hereby give rise to ${ }^{13} \mathrm{C}$ enrichment in TCA cycle intermediates and derived amino acids (presented as the average ${ }^{13} \mathrm{C}$ accumulation, molecular carbon labeling, MCL [35]). In the TCA cycle, the highest ${ }^{13} \mathrm{C}$ accumulation from both $\left[\mathrm{U}-{ }^{13} \mathrm{C}\right]$ $\mathrm{C} 8$ and $\left[\mathrm{U}-{ }^{13} \mathrm{C}\right] \mathrm{C} 10$ metabolism was found in citrate (C8: $17.4 \pm 0.2 \%$, C10: $18.9 \pm 0.8 \%$ ), whereas it was much lower for $\alpha$-ketoglutarate (C8: $5.4 \pm 0.6 \%, C 10: 5.9 \pm 0.3 \%)$ and malate (C8: $6.5 \pm 0.2 \%, \mathrm{C} 10: 6.5 \pm 0.2 \%$ ). Of the derived amino acids, the highest ${ }^{13} \mathrm{C}$ accumulation was found in glutamine (C8: $28.5 \pm 0.4 \%, C 10: 35.0 \pm 0.8 \%$ ), whereas it was around four times lower for aspartate (C8: $5.8 \pm 0.2 \%$, C10: $5.4 \pm 0.2 \%$ ), glutamate (C8: $7.3 \pm 0.2 \%$, C10: $7.3 \pm 0.3 \%)$ and GABA (C8: $7.9 \pm 0.7 \%, \mathrm{C} 10$ : $6.4 \pm 0.2 \%)$. The only difference between the two fatty acids was observed in glutamine, where metabolism of $\left[\mathrm{U}_{-}{ }^{13} \mathrm{C}\right] \mathrm{C} 10$ led to larger ${ }^{13} \mathrm{C}$ accumulation than $\left[\mathrm{U}_{-}{ }^{13} \mathrm{C}\right]$ C8. We found no differences in the absolute pool sizes of amino acids between the $\left[\mathrm{U}_{-}{ }^{13} \mathrm{C}\right] \mathrm{C} 8$ and $\left[\mathrm{U}_{-}{ }^{13} \mathrm{C}\right] \mathrm{C} 10$ incubations (Additional file 1: Table S1). These results show that both $\mathrm{C} 8$ and $\mathrm{C} 10$ are actively metabolized in brain slices and that the extent of metabolism between the two fatty acids is generally comparable. Furthermore, since glutamine is selectively synthesized in astrocytes [26], the preferential ${ }^{13} \mathrm{C}$ accumulation in this amino acid suggesting that astrocytes are the primary cellular compartment of $\mathrm{C} 8$ and $\mathrm{C} 10$ metabolism in brain slices.

\section{C8 and C10 stimulate mitochondrial respiration in cultured astrocytes}

MCFAs can serve as metabolic substrates and support mitochondrial respiration in multiple tissues $[2,4]$. To assess whether this was the case in astrocytes, we preincubated cultured astrocytes in media supplemented with $\mathrm{C} 8, \mathrm{C} 10$ or the combination in addition to glucose (Fig. 2A) and determined the oxygen consumption rate (OCR) using the Seahorse XFe96 flux analyzer (Fig. 2B). We found that $\mathrm{C} 8, \mathrm{C} 10$ and the combination increased the basal, i.e. non-stimulated, OCR of the cultured astrocytes (Fig. 2C). The basal OCR is comprised of the OCR related to ATP production and the proton leak (Fig. 2B), the latter reflecting the flow of protons across the mitochondrial membrane not linked to ATP production [38]. We found that the presence of $\mathrm{C} 10$ selectively elevated the proton leak in the cultured astrocytes (Fig. 2D), whereas $\mathrm{C} 8$ alone increased the OCR related to ATP production (Fig. 2E). Finally, when the oxidative capacity was unleashed by the uncoupling agent FCCP, we observed that $\mathrm{C} 8, \mathrm{C} 10$ as well as the combination, elevated the OCR of the cultured astrocytes (Fig. 2F). These results demonstrate that both $\mathrm{C} 8$ and $\mathrm{C} 10$ are able to stimulate respiration in cultured astrocytes, albeit via distinct mitochondrial mechanisms.

\section{C10 is preferred over C8 as a metabolic substrate in brain slices}

So far, we have shown that C8 and C10 can serve as metabolic substrates in astrocytes promoting glutamine synthesis and stimulating mitochondrial respiration. Next, we wanted to investigate if there was any metabolic 


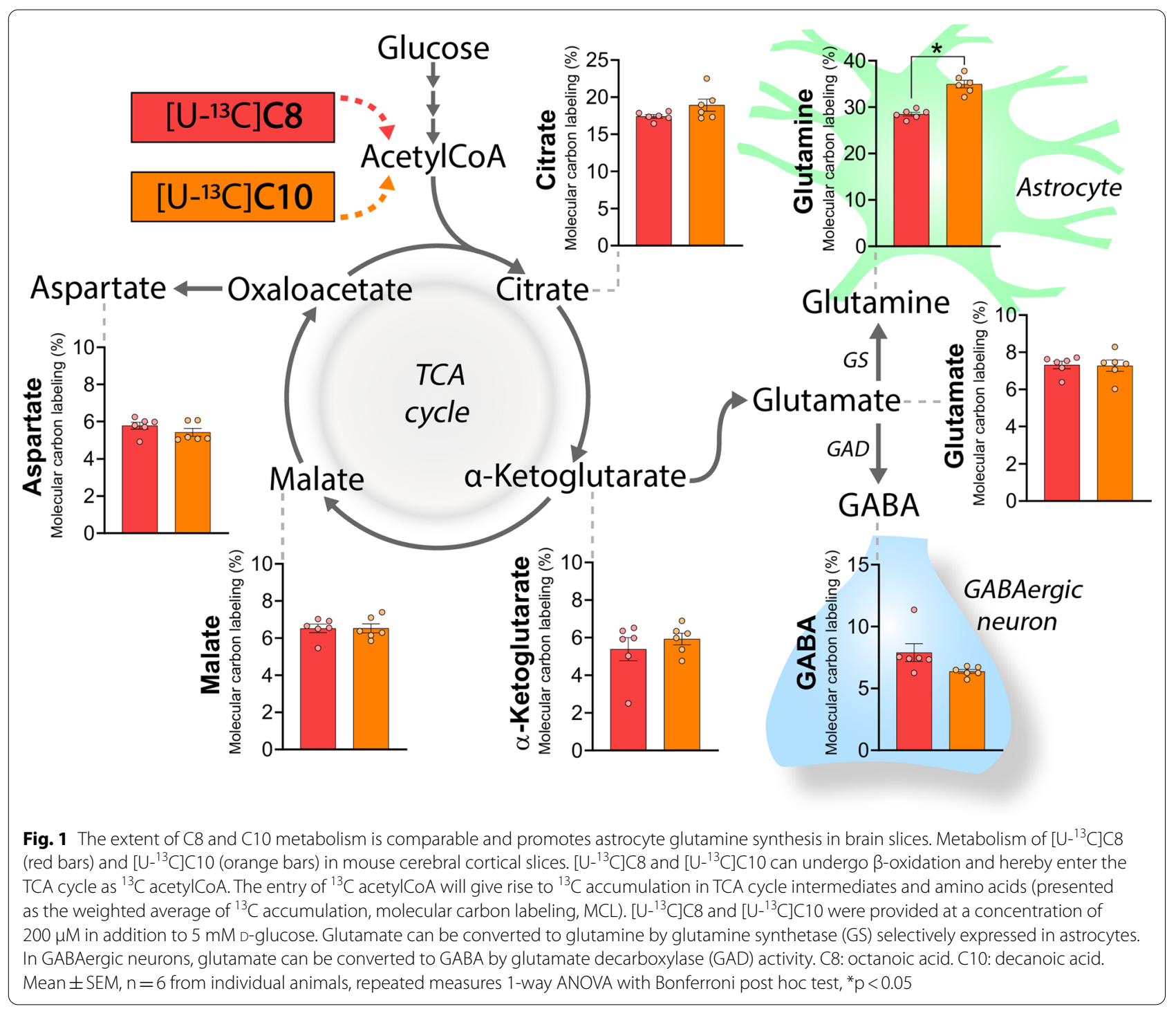

preference between the two fatty acids. To this end, we performed a competition assay, in which brain slices were incubated in the presence of either $\left[\mathrm{U}_{-}{ }^{13} \mathrm{C}\right] \mathrm{C} 8$ or $\left[\mathrm{U}_{-}{ }^{13} \mathrm{C}\right]$ $\mathrm{C} 10$, but now also with a competing unlabeled (i.e. ${ }^{12} \mathrm{C}$ ) fatty acid (Fig. 3). Metabolism of an unlabeled ${ }^{12} \mathrm{C}$ fatty acid will dilute the ${ }^{13} \mathrm{C}$ labeling, and so the metabolic preference of each fatty acid can be determined. When the slices were exposed to $\left[\mathrm{U}_{-}{ }^{13} \mathrm{C}\right] \mathrm{C} 8$ in the presence of unlabeled ${ }^{12} \mathrm{C} 10$, we found large reductions in the ${ }^{13} \mathrm{C}$ accumulation of all measured metabolites (in the range of $12-21 \%$ of control). In contrast, the metabolism of $\left[\mathrm{U}^{13}{ }^{13} \mathrm{C}\right] \mathrm{C} 10$ was only found to be reduced in GABA $(65.4 \pm 3.4 \%$ of control) and glutamine $(83.1 \pm 1.7 \%$ of control) when unlabeled ${ }^{12} \mathrm{C} 8$ was present. These results demonstrate that metabolism of $\mathrm{C} 10$ is predominant over that of $\mathrm{C} 8$ in the brain slices when the two fatty acids are provided together. Furthermore, we also included the ketone body $\beta$-hydroxybutyrate $(\beta \mathrm{HB})$ in the competition experiments. $\beta \mathrm{HB}$ also enters metabolism as acetylCoA units, but is oxidized to a larger extent in neurons than in astrocytes $[29,39]$. We found that unlabeled ${ }^{12} \mathrm{C}$ $\beta \mathrm{HB}$ had little influence on both $\left[\mathrm{U}_{-}{ }^{13} \mathrm{C}\right] \mathrm{C} 8$ and $\left[\mathrm{U}_{-}{ }^{13} \mathrm{C}\right]$ $\mathrm{C} 10$ metabolism in the brain slices (Additional file 1: Fig. S1). Furthermore, metabolism of unlabeled ${ }^{12} \mathrm{C} 8$ and ${ }^{12} \mathrm{C} 10$ was only able to reduce the ${ }^{13} \mathrm{C}$ accumulation from $\left[\mathrm{U}-{ }^{13} \mathrm{C}\right] \beta \mathrm{HB}$ metabolism in citrate and glutamine (Additional file 1: Fig. S2), confirming that the substrates are oxidized in separate cellular compartments. Again, no changes in the absolute pool sizes of amino acids were observed (Additional file 1: Table S1). 

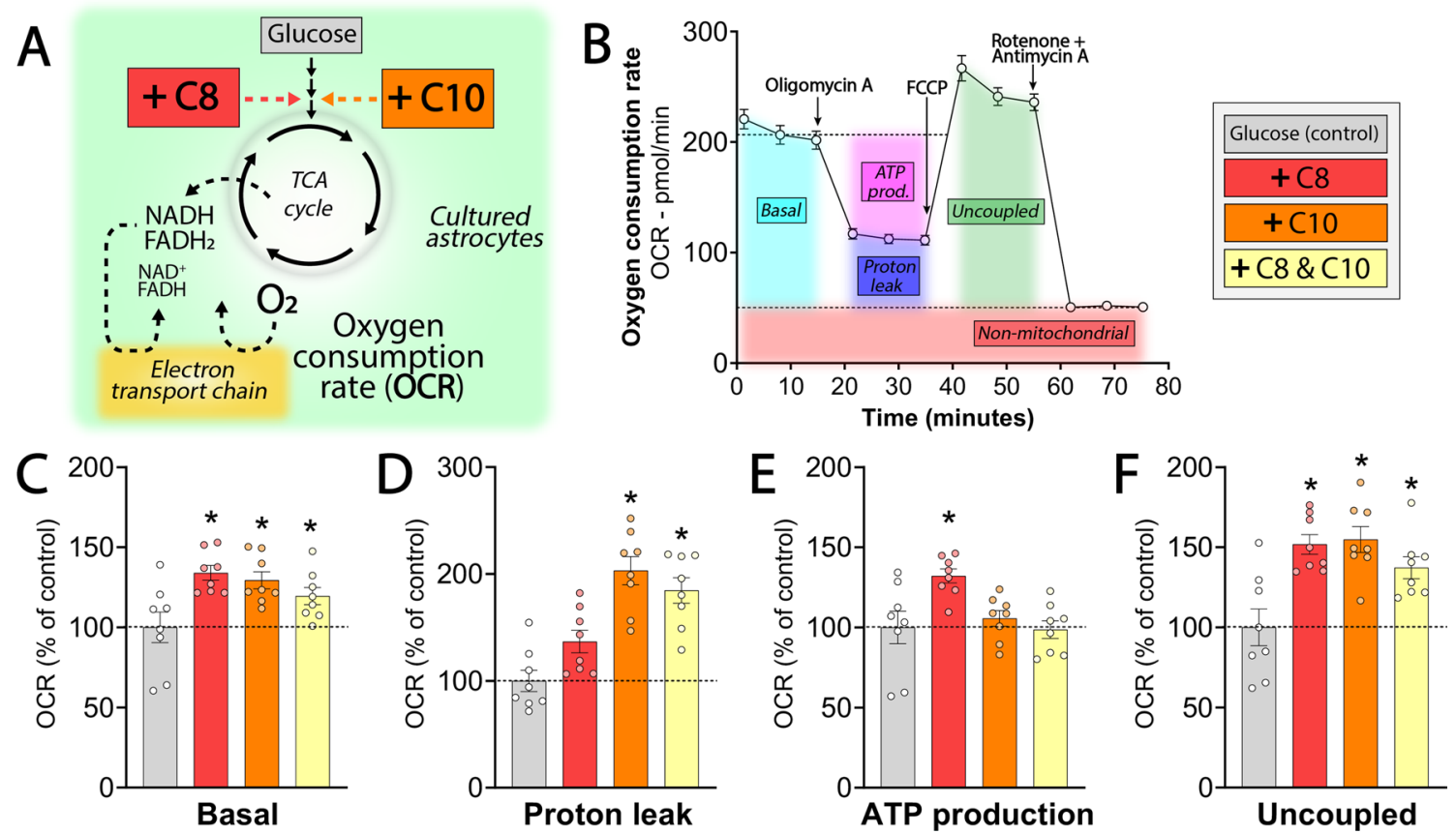

Fig. 2 C8 and C10 stimulate mitochondrial respiration in cultured astrocytes via distinct mechanisms. A Cultured astrocytes were provided C8, C10 or the combination and the mitochondrial oxygen consumption rate (OCR) was assessed. The astrocytes were pre-incubated with the MCFAs $(200 \mu \mathrm{M})$ for $1 \mathrm{~h}$ in addition to $2.5 \mathrm{mM}$ D-glucose. B Seahorse XFe96 assay overview. During the assay three compounds were injected: (1) the ATP synthase inhibitor oligomycin A, (2) the mitochondrial uncoupler FCCP, (3) the electron transport chain inhibitors rotenone and antimycin A. From the Seahorse assay multiple respiratory parameters can be assessed: non-stimulated OCR (Basal), mitochondrial proton leak, OCR related to ATP production (ATP prod.), maximal uncoupled OCR (uncoupled) and the OCR unrelated to mitochondrial processes (non-mitochondrial). The non-mitochodrial OCR was subtracted from all data points prior to analysis. C-F Respiratory parameters of cultured astrocytes provided C8 (red bars), C10 (orange bars) or the combination (yellow bars). Data is presented as OCR, relative to the OCR of glucose alone (grey bars, control)). C8: octanoic acid. C10: decanoic acid. Mean \pm SEM, $n=8$ from individual batches of cultures, repeated measures 1-way ANOVA with Bonferroni post hoc test, ${ }^{*} \mathrm{p}<0.05$

\section{Metabolism of C8 and C10 is independent of carnitine palmitoyltransferase I in brain slices}

Given that the extent of ${ }^{13} \mathrm{C}$ accumulation between $\mathrm{C} 8$ and $\mathrm{C} 10$ was comparable when metabolized individually (Fig. 1), it was surprising that $\mathrm{C} 10$ was preferred over C8 so extensively when applied together (Fig. 3). This could be explained by $\mathrm{C} 8$ and $\mathrm{C} 10$ competing for the same transport mechanism. Cellular and mitochondrial uptake of MCFAs is driven by passive diffusion [2, 40]. However, in a neuronal-like cell line mitochondrial uptake of C8 and $\mathrm{C} 10$ was recently suggested to be partially mediated by carnitine palmitoyltransferase I (CPT-1), an enzyme important for long-chain fatty acid transport [41]. To investigate if this was the case in brain slices, we next examined the effect of the irreversible CPT-1 inhibitor etomoxir on metabolism of $\left[\mathrm{U}_{-}{ }^{13} \mathrm{C}\right] \mathrm{C} 8$ and $\left[\mathrm{U}_{-}{ }^{13} \mathrm{C}\right] \mathrm{C} 10$ (Fig. 4). Etomoxir was applied at $100 \mu \mathrm{M}$, which effectively inhibit long-chain fatty acid metabolism in both dissected brain tissue and cultured astrocytes [42]. We did not observe any significant alterations in ${ }^{13} \mathrm{C}$ accumulation of the measured metabolites when etomoxir was present during the incubation. These results indicate that metabolism of both $\left[\mathrm{U}_{-}{ }^{13} \mathrm{C}\right] \mathrm{C} 8$ and $\left[\mathrm{U}_{-}{ }^{13} \mathrm{C}\right] \mathrm{C} 10$ is independent of CPT-1 in brain slices, and $\mathrm{C} 8$ and $\mathrm{C} 10$ must therefore enter the mitochondria via other mechanisms. As expected, metabolism of $\left[\mathrm{U}_{-}{ }^{13} \mathrm{C}\right] \beta \mathrm{HB}$ was likewise unaffected by etomoxir (Additional file 1: Fig. S3).

\section{Astrocyte glutamine from C8 and C10 metabolism is utilized for neuronal GABA synthesis}

To further explore the significance of the astrocyte glutamine synthesis from metabolism of $\mathrm{C} 8$ and C10, we finally investigated the effect of glutamine synthetase (GS) inhibition on metabolism of $\left[\mathrm{U}_{-}{ }^{13} \mathrm{C}\right] \mathrm{C} 8$ and $\left[\mathrm{U}_{-}{ }^{13} \mathrm{C}\right]$ $\mathrm{C} 10$ in the cerebral cortical slices (Fig. 5). The GS inhibitor methionine sulfoximine (MSO) was applied at $5 \mathrm{mM}$, which we have previously shown is sufficient to effectively inhibit GS activity in brain slices [43]. As expected, GS inhibition abolished the ${ }^{13} \mathrm{C}$ accumulation in glutamine from metabolism of $\left[\mathrm{U}_{-}{ }^{13} \mathrm{C}\right] \mathrm{C} 8$ and $\left[\mathrm{U}_{-}{ }^{13} \mathrm{C}\right] \mathrm{C} 10$ (C8: $8.7 \pm 1.9 \%$ of control, $\mathrm{C} 10: 3.7 \pm 0.5 \%$ of control). Interestingly, all TCA cycle intermediates and the derived amino 


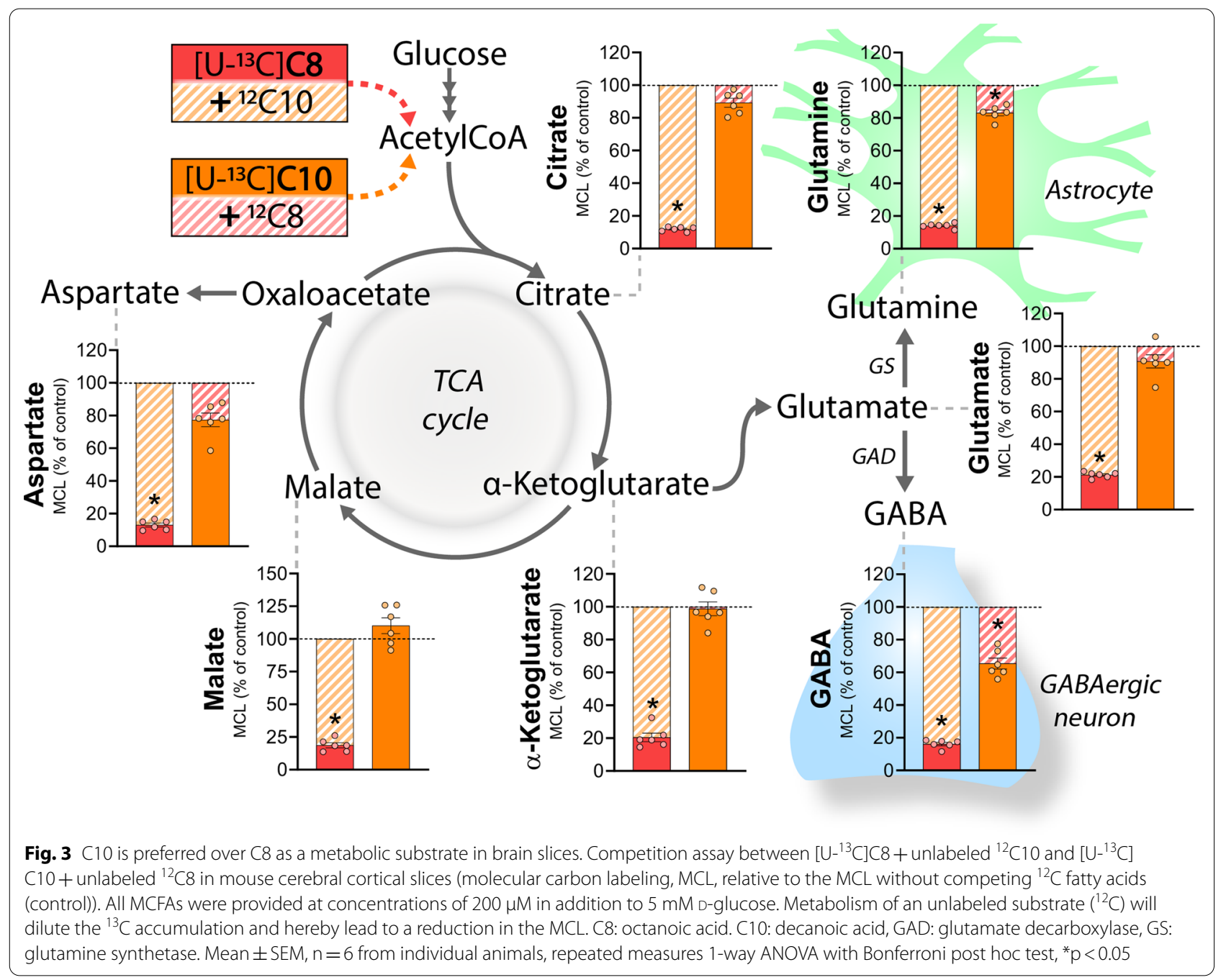

acids aspartate and glutamate exhibited large increases in ${ }^{13} \mathrm{C}$ accumulation from metabolism of $\left[\mathrm{U}_{-}{ }^{13} \mathrm{C}\right] \mathrm{C} 8$ and $\left[\mathrm{U}^{13} \mathrm{C}\right] \mathrm{C} 10$ when glutamine synthesis was inhibited by MSO (in the range of $156-267 \%$ of control). In contrast, GS inhibition selectively led to large reductions in the ${ }^{13} \mathrm{C}$ accumulation in GABA (C8: $23.4 \pm 1.5 \%$ of control, C10: $25.4 \pm 1.2 \%$ of control) from both $\left[\mathrm{U}_{-}{ }^{13} \mathrm{C}\right] \mathrm{C} 8$ and $\left[\mathrm{U}_{-}{ }^{13} \mathrm{C}\right]$ C10 metabolism. Since astrocyte-derived glutamine is a crucial substrate for neuronal GABA synthesis [44], these results demonstrate that the glutamine synthesized by metabolism of $\mathrm{C} 8$ and $\mathrm{C} 10$ in astrocytes is utilized in neurons to maintain the GABA pool. MSO only decreased the ${ }^{13} \mathrm{C}$ accumulation in glutamine, but not in GABA, from $\left[\mathrm{U}_{-}{ }^{13} \mathrm{C}\right] \beta \mathrm{HB}$ metabolism which is expected as $\beta \mathrm{HB}$ is primarily metabolized in neurons (Additional file 1: Fig. S4).

\section{Discussion}

Here we demonstrate that the MCFAs C8 and C10 are oxidatively metabolized in brain slices and promotes astrocyte glutamine synthesis. We found that the overall extent of metabolism was comparable between $\mathrm{C} 8$ and $\mathrm{C} 10$, but $\mathrm{C} 10$ was preferred over $\mathrm{C} 8$ as a metabolic substrate when both fatty acids were present. Both $\mathrm{C} 8$ and C10 stimulated mitochondrial respiration in cultured astrocytes, where C8 elevated respiration linked to ATP synthesis and $\mathrm{C} 10$ increased the mitochondrial proton leak. Finally, we found that metabolism of both $\mathrm{C} 8$ and $\mathrm{C} 10$ was CPT-1 independent and that the elevated astrocyte glutamine synthesis from $\mathrm{C} 8$ and $\mathrm{C} 10$ metabolism is utilized for neuronal GABA synthesis in the brain slices (findings summarized in Fig. 6). 


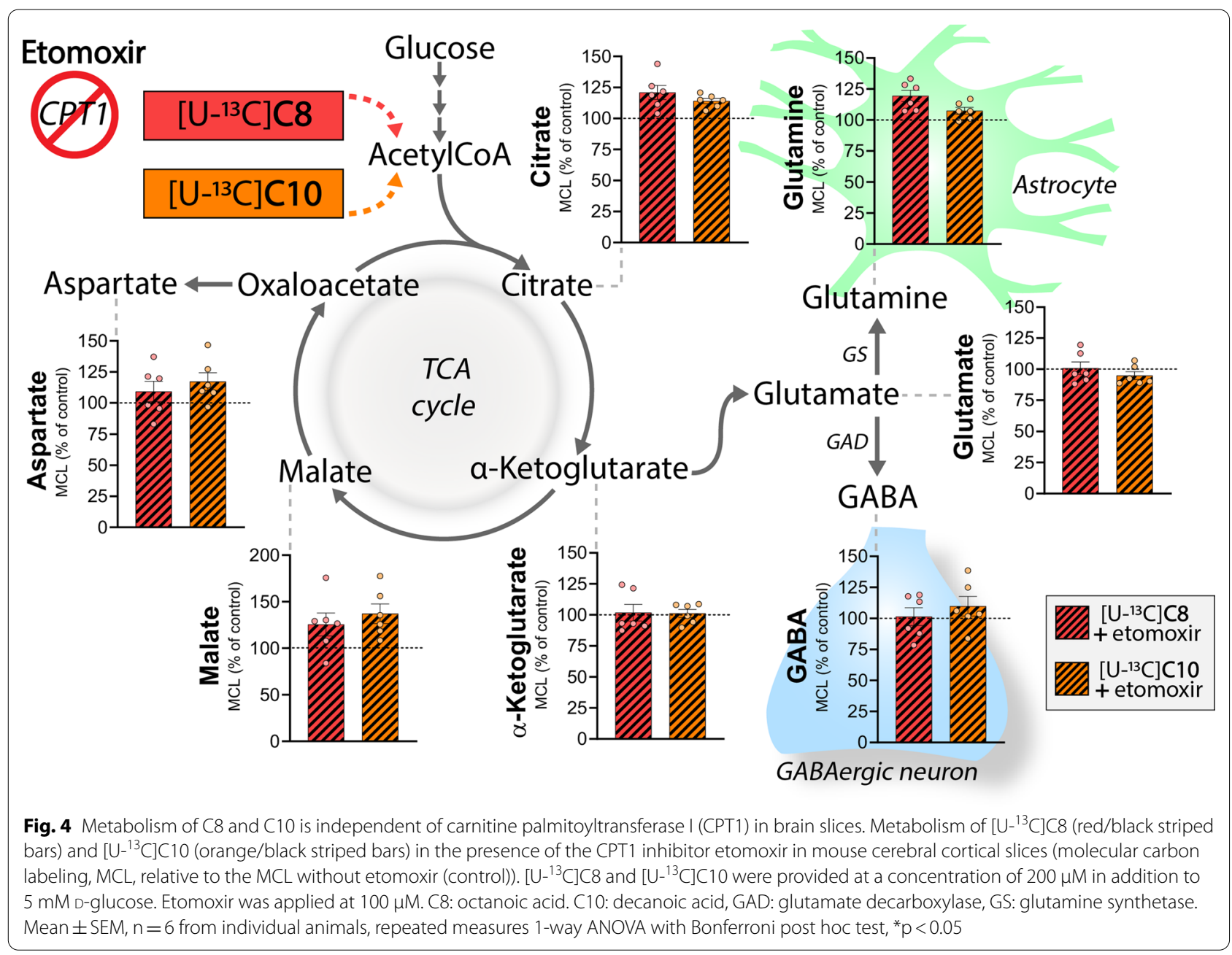

\section{Astrocyte metabolism of C8 and C10}

MCFAs have long been known to be substrates, albeit minor ones, for cerebral oxidative metabolism $[1,4,45]$. It has previously been reported that in-vivo metabolism of radiolabeled C8 leads to a larger enrichment in glutamine than in glutamate, suggesting a preferential astrocyte metabolism of C8 $[28,30]$. Here we extend this finding to acute brain slices, where we show that metabolism not only of $\mathrm{C} 8$, but also of $\mathrm{C} 10$, is promoting glutamine synthesis in astrocytes. The preferential astrocyte metabolism of MCFAs has further been confirmed in cell cultures, where only astrocytes were able to metabolize $\left[1-{ }^{14} \mathrm{C}\right] \mathrm{C} 8$, whereas neurons and oligodendrocytes were not [29]. Here we also report that the extent of C8 and C10 metabolism in brain slices, based on ${ }^{13} \mathrm{C}$ accumulation in TCA cycle intermediates and amino acids, was generally comparable. A recent study assessed $\mathrm{CO}_{2}$ generation from metabolism of $\left[1-{ }^{14} \mathrm{C}\right] \mathrm{C} 8$ / $\mathrm{C} 10$ in the neuronal-like SH-SY5Y cell line. Based on the
$\mathrm{CO}_{2}$ generation, the authors reported that the oxidation of C8 was around 6 times higher than that of C10 [41], which is in contrast to our findings in the acute brain slices where the extent of $\mathrm{C} 8$ and $\mathrm{C} 10$ metabolism was comparable (Fig. 1). This discrepancy is likely explained by the different preparations, as the SH-SY5Y is a neuroblastoma cell line with neuronal-like properties [46], whereas brain slices are a complex preparation containing all types of cerebral cells, including the primary cells of MCFA metabolism in the brain, the astrocytes. When the brain slices were provided both $\mathrm{C} 8$ and $\mathrm{C} 10$, we found that metabolism of $\mathrm{C} 10$ was predominant over that of $\mathrm{C} 8$ (Fig. 3), which may indicate competition in mitochondrial transport or metabolism of $\mathrm{C} 8$ and C10. It has also recently been reported that $\mathrm{CPT}-1$ inhibition reduced the oxidative metabolism of both $\mathrm{C} 8$ and $\mathrm{C} 10$ in the $\mathrm{SH}-\mathrm{SY} 5 \mathrm{Y}$ cells [41]. This is surprising as MCFAs metabolism should be carnitine independent $[2,47]$, which we also found to be the case in brain slices (Fig. 4). Our observation that 


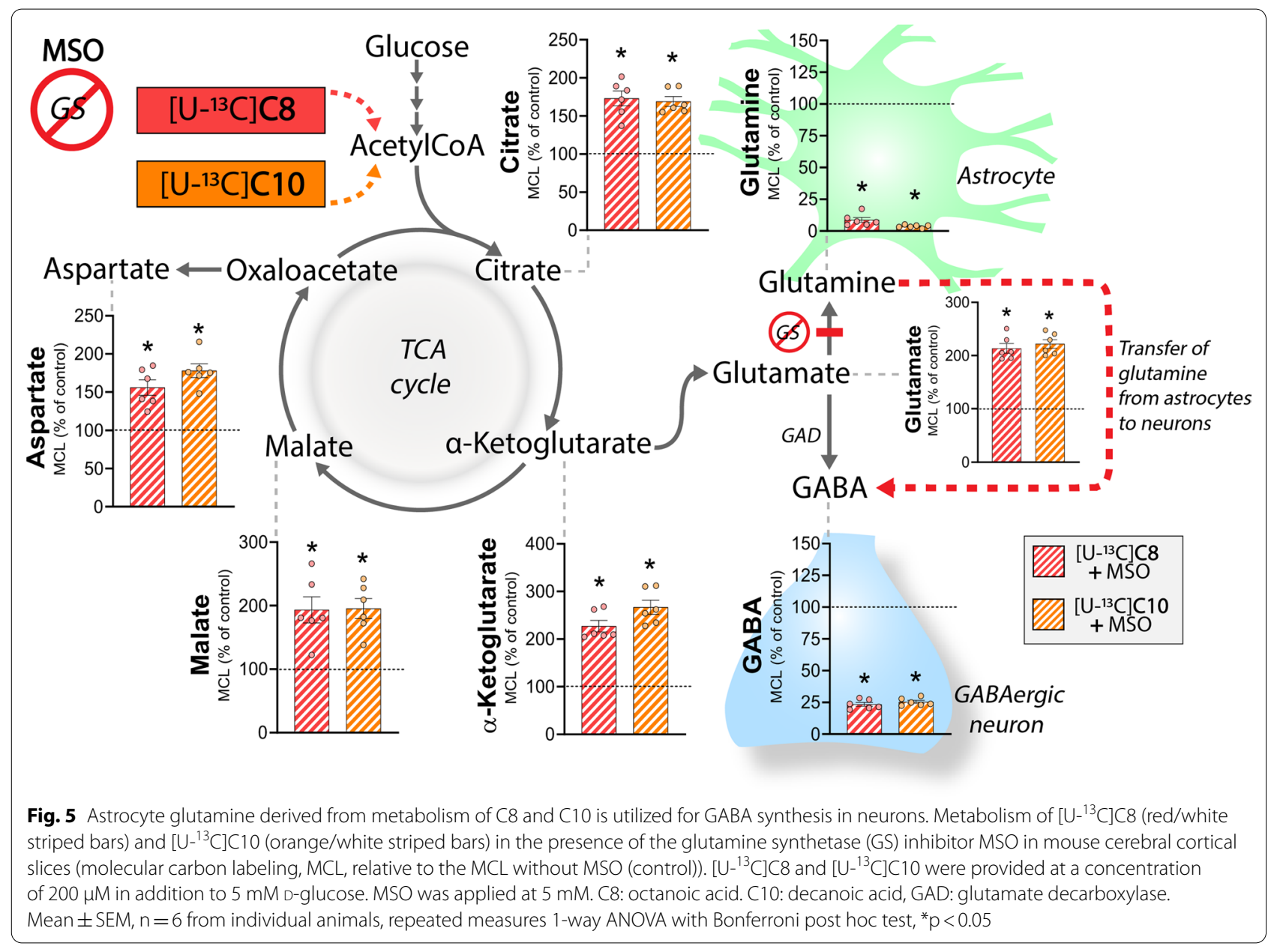

C10 was preferred over $\mathrm{C} 8$ as a metabolic substrate in the brain slices may instead be explained by differential substrate affinities for C8 and C10 of the enzymes catalyzing MCFA metabolism. Indeed, the enzyme initiating mitochondrial MCFA $\beta$-oxidation, the medium-chain acylCoA dehydrogenase, has been shown to have a higher substrate affinity towards C10 than C8 [48]. Furthermore, $\mathrm{C} 10$ also has a larger membrane permeability than $\mathrm{C} 8$, due to the longer carbon chain, which increases diffusion across the cell and mitochondrial membranes [40], which may also contribute to the observed preferential metabolism of $\mathrm{C} 10$ over $\mathrm{C} 8$. Although astrocytes are the main cellular compartment of MCFA metabolism, it was recently demonstrated that a subset of neurons in the hypothalamus have a large capacity for C8 oxidation [49]. In these hypothalamic neurons, $\mathrm{C} 8$ metabolism regulate neuronal excitability and food intake, which underlines the complexity and importance of regional brain energy metabolism. Further studies are needed to explore other potential functions of MCFA metabolism in the brain, both on a regional and cell-specific level.

\section{Mitochondrial effects of C8 and C10 in astrocytes}

Both $\mathrm{C} 8$ and $\mathrm{C} 10$ can be utilized as mitochondrial fuels in several different tissues including the brain $[2,4]$. Here, we found that the addition of $\mathrm{C} 8, \mathrm{C} 10$ and the combination was able to stimulate both basal and uncoupled mitochondrial respiration in cultured astrocytes (Fig. 2). Our findings are in contrast to a report by Thevenet et al. showing that acute exposure to $\mathrm{C} 8$ and $\mathrm{C} 10$ was unable to stimulate the OCR of cultured induced pluripotent stem cell-derived human neurons and astrocytes [50]. Although not significant, the study reported that $\mathrm{C} 8 \mathrm{had}$ a tendency to increase the overall OCR, whereas C10 had a tendency towards reduced ATP-dependent OCR, in the cultured astrocytes [50]. These tendencies are in line with our findings that $\mathrm{C} 8$ increased the respiration linked to ATP production, whereas $\mathrm{C} 10$ increased the proton leak in the cultured astrocytes. Our observations further confirm a recent study in cultured astrocytes, showing that both $\mathrm{C} 8$ and $\mathrm{C} 10$ were able to increase basal respiration, whereas $\mathrm{C} 10$ selectively increased the proton leak relative to pyruvate oxidation [32]. The proton leak is defined as 


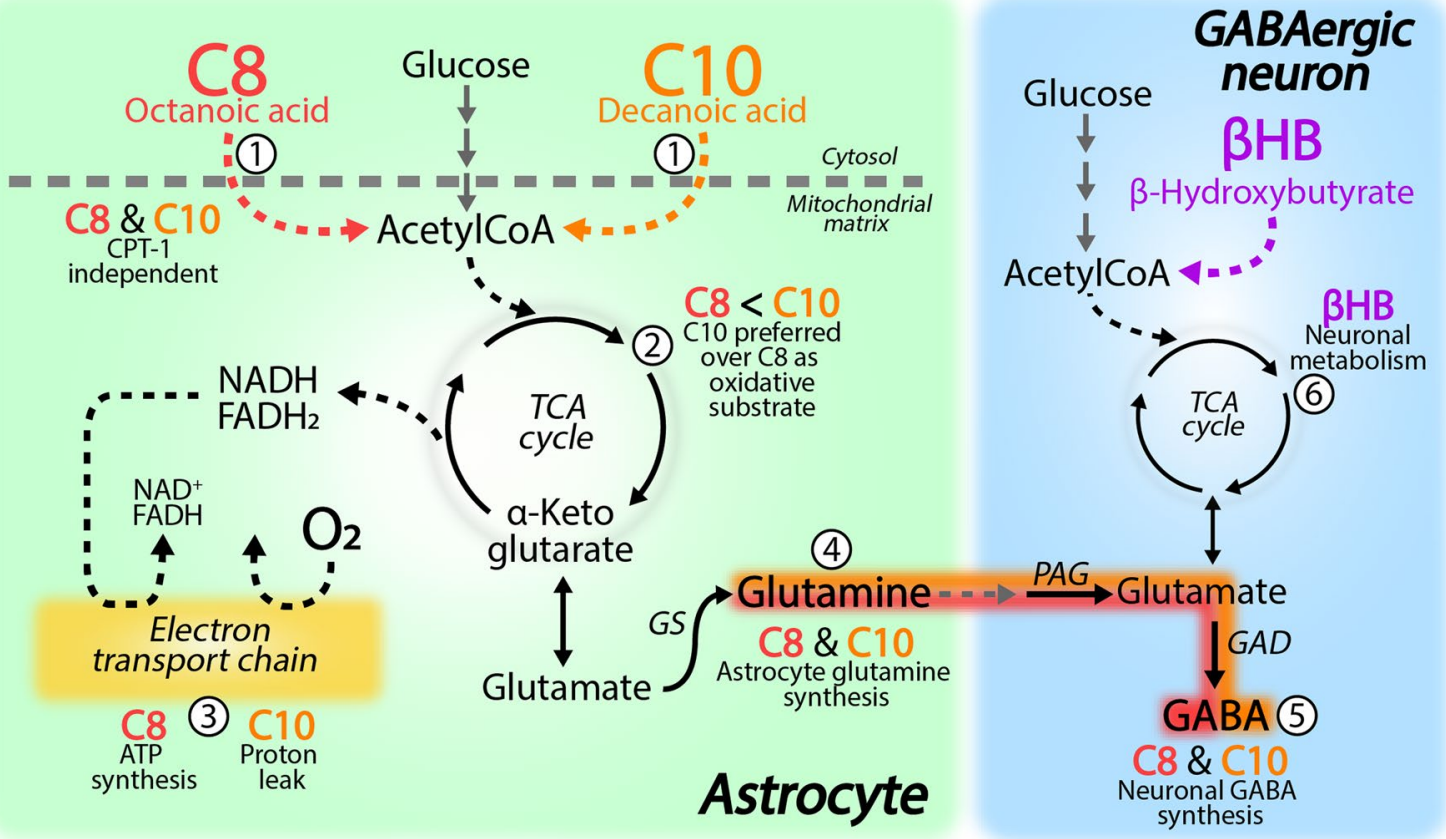

Fig. 6 Overview of $\mathrm{C} 8$ and $\mathrm{C} 10$ metabolism in brain slices. (1) Both C8 and C10 metabolism was unaffected by the carnitine palmitoyltransferase I (CPT-1) inhibitor etomoxir. (2) When provided alone, the extent of C8 and C10 metabolism was comparable, but when provided together C10 was preferred over C8 as a metabolic substrate. (3) In cultured astrocytes, C8 selectively increased the respiration linked to ATP production, whereas the presence of $\mathrm{C} 10$ elevated the mitochondrial proton leak. (4) Both C8 and C10 is utilized for glutamine synthesis. Since glutamine is selectively synthesized in astrocytes, this signifies that astrocytes are the primary cellular compartment for C8 and C10 metabolism. (5) When glutamine synthesis from C8 and C10 metabolism was inhibited, a selective reduction was observed in neuronal GABA synthesis. This demonstrates that the glutamine generated by astrocyte metabolism of $\mathrm{C} 8$ and $\mathrm{C} 10$ is used for neuronal GABA synthesis. (6) The ketone body $\beta$-hydroxybutyrate ( $\beta H B$ ) did not compete, to any significant extent, with C8 and C10 metabolism supporting the notion that ketone bodies are primarily utilized by neurons

the flow of protons across the inner mitochondrial membrane unrelated to ATP synthesis and is intimately coupled to the generation of harmful reactive oxygen species (ROS) [38]. Intriguingly, a mild increase in the proton leak is protective against ROS generation $[38,51]$ and the elevated proton leak induced by $\mathrm{C} 10$ may therefore have antioxidant properties. Furthermore, $\mathrm{C} 10$ has been shown to exert multiple other antioxidant effects, including regulation of antioxidant gene expression [32], catalase activity [52] and glutathione content [53]. Treatment with $\mathrm{C} 10$, but not $\mathrm{C} 8$, in SH-SY5Y cells has also been shown to increase mitochondrial biogenesis [52], potentially via PPAR signaling $[54,55]$. Collectively these findings show that $\mathrm{C} 10$ is not just a mitochondrial fuel, but can exert several beneficial effects on mitochondrial bioenergetics via multiple distinct mechanisms.

\section{Effects of C8 and C10 metabolism on neuron-astrocyte metabolic coupling and neurotransmitter recycling}

Energy and neurotransmitter metabolism in neurons and astrocytes is tightly coupled [18]. Fatty acid transfer between neurons and astrocytes is gaining attention [56, 57] and MCFAs have also been suggested to take part in the transcellular metabolic coupling [3]. Several studies have shown that $\mathrm{C} 10$ is able to induce astrocyte lactate production, whereas $\mathrm{C} 8$ stimulates astrocyte ketone body production $[50,53,58,59]$, both of which may be transferred to neurons to support oxidative metabolism. Another crucial metabolite transferred from astrocytes to neurons is glutamine, which serves an essential role as the primary precursor of neuronal glutamate and GABA synthesis [20-22, 44]. When we inhibited glutamine synthesis from $\mathrm{C} 8$ and $\mathrm{C} 10$ metabolism in brain slices using $\mathrm{MSO}$, the ${ }^{13} \mathrm{C}$ accumulation in glutamine and GABA was decreased, while it was elevated for the rest of the measured metabolites (Fig. 5). We have previously described similar effects of MSO on metabolism of the well-known astrocytic substrate $\left[1,2-{ }^{13} \mathrm{C}\right]$ acetate [43], further supporting that astrocytes are the main cellular compartment of C8 and C10 metabolism. Furthermore, we have previously demonstrated that transfer of astrocyte-derived glutamine to neurons is maintained in our slice incubation set-up [43,60], implying that the decreased neuronal GABA synthesis in the presence of MSO is indeed caused by the absent astrocyte glutamine supply. Insufficient astrocyte glutamine 
synthesis can lead to seizures [24] and reduced expression of GS has been found in the epileptic hippocampus [23]. Elevated neuronal GABA synthesis, linked to increased glutamine supply from astrocyte metabolism of $\mathrm{C} 8$ and $\mathrm{C} 10$, could therefore aid to maintain the inhibitory tone of the brain and hereby serve as an anti-convulsant mechanism of $\mathrm{C} 8$ and $\mathrm{C} 10$ supplementation. In addition, Lee et al. recently demonstrated that long-term C10 exposure leads to GABA synthesis and accumulation in cultured astrocytes [59], which may further aid to sustain tonic inhibition [61, 62]. Treatment with MCTs, containing triglycerides of $\mathrm{C} 8$ and $\mathrm{C} 10$, leads to increased hepatic production of ketone bodies, which has been hypothesized to be the main mechanism behind the beneficial effects in epilepsy [9]. When we provided the ketone body $\beta \mathrm{HB}$ as a competing metabolic substrate to $\mathrm{C} 8$ and $\mathrm{C} 10$ in brain slices, we observed scarce effects (Additional file 1: Fig. S1 and S2). These observations are in line with the notion that $\mathrm{C} 8$ and $\mathrm{C} 10$ are primarily metabolized in astrocytes, whereas $\beta \mathrm{HB}$ is metabolized to larger extent in neurons $[29,39]$. This clear metabolic compartmentation is highly interesting in relation to dietary MCT treatment, as it will provide specific cellular metabolic substrates; ketone bodies for the neurons to support oxidative metabolism, and C8 and C10 for the astrocytes, which leads to elevated glutamine synthesis (Fig. 6). These notions are in line with a study showing that $\beta \mathrm{HB}$, but not $C 8$, could support neuronal signaling in hippocampal brain slices during low-glucose conditions [63]. However, the same study reported that $\mathrm{C} 8$ increased the neuronal recovery rate [63], which in the light of the present study, could be mediated via increased astrocyte glutamine supply. In addition to direct metabolic effects, C10 may serve several signaling purposes in the brain $[59,64]$, and is able to directly inhibit AMPA receptors [65], suggesting multiple mechanisms underlying the anti-epileptic effects of C10. Finally, astrocyte dysfunction is gaining attention in several neurodegenerative diseases [66] and we have demonstrated inadequate astrocyte glutamine supply in mouse models of both Alzheimer's and Huntington's disease [25, 60]. Interestingly, C8 and C10 supplementation has been shown to improve cognitive function in patients with mild cognitive impairment and Alzheimer's disease [68] and are gaining attention in several other diseases [5]. C8 and C10 could exert these beneficial effects, in part, by enhancing astrocyte glutamine synthesis and hereby improve neuronal neurotransmitter homeostasis. These notions encourage further studies into the molecular and cellular mechanisms of MCFA supplementation in neurodegeneration and other diseases.

\section{Abbreviations}

BHB: $\beta$-Hydroxybutyrate; C8: Octanoic acid; C10: Decanoic acid; CPT-1: Carnitine palmitoyltransferase l; GS: Glutamine synthetase; MCFA: Medium-chain fatty acid; MCT: Medium-chain triglyceride; MSO: Methionine sulfoximine; OCR: Oxygen consumption rate; PAG: Phosphate-activated glutaminase; TCA :Tricarboxylic acid.

\section{Supplementary Information}

The online version contains supplementary material available at https://doi. org/10.1186/s13041-021-00842-2.

Additional file 1: Figure S1. Unlabeled ${ }^{12} \mathrm{C}-\beta \mathrm{HB}$ competes poorly with $\left[\mathrm{U}-{ }^{13} \mathrm{C}\right] \mathrm{C} 8$ and $\left[\mathrm{U}-{ }^{13} \mathrm{C}\right] \mathrm{C} 10$ in brain slices. Figure S2. Unlabeled ${ }^{12} \mathrm{C} 8$ and ${ }^{12} \mathrm{C} 10$ only dilutes ${ }^{13} \mathrm{C}$ accumulation in citrate and glutamine from $\left[\mathrm{U}-{ }^{13} \mathrm{C}\right] \beta \mathrm{HB}$ metabolism in brain slices. Table S1. Intracellular amino acid amounts of incubated cerebral cortical slices. Figure S3. Metabolism of $\beta \mathrm{HB}$ is independent of carnitine palmitoyltransferase I (CPT1) in brain slices. Figure S4. Inhibition of astrocyte glutamine derived from metabolism of $\beta H B$ does not affect neuronal GABA synthesis.

\section{Acknowledgements}

John Velde Andersen is acknowledged for excellent technical support. The Scholarship of Peter \& Emma Thomsen is gratefully acknowledged for personal financial support to JVA \& EWW.

\section{Authors' contributions}

JVA performed all slice incubations. JVA and EJ performed Seahorse experiments. EW and NU assisted with sample analysis. All authors interpreted the data and provided critical input to the final manuscript. JVA, KB \& BIA conceived the overall project and JVA wrote the original manuscript. All authors read and approved the final manuscript.

\section{Funding}

This study was financially supported by the Lundbeck Foundation (JVA, R3332019-1244), the Hørslev Foundation (BIAG) and the Australian National Health and Medical Research Council (KB, APP1186025).

\section{Availability of data and materials}

All data of this study is available from the corresponding authors upon request.

\section{Declarations}

\section{Ethics approval and consent to participate}

Experiments were approved by the Danish National Ethics Committee and performed in accordance with the European Convention (ETS 123 of 1986).

\section{Consent for publication}

Not applicable.

\section{Competing interests}

The authors declare that they have no competing interests.

\section{Author details}

'Department of Drug Design and Pharmacology, Faculty of Health and Medical Sciences, University of Copenhagen, Universitetsparken 2, 2100 Copenhagen E, Denmark. ${ }^{2}$ Department of Pharmacology, School of Biomedical Sciences, The University of Queensland, St. Lucia, Australia.

Received: 28 May 2021 Accepted: 22 August 2021

Published online: 03 September 2021

References

1. Dienel GA. Brain glucose metabolism: integration of energetics with function. Physiol Rev. 2019;99:949-1045. 
2. Schönfeld P, Wojtczak L. Short- and medium-chain fatty acids in energy metabolism: the cellular perspective. J Lipid Res. 2016;57:943-54.

3. Romano A, Koczwara JB, Gallelli CA, Vergara D, Micioni D, Bonaventura MV, Gaetani S, Giudetti AM. Fats for thoughts: an update on brain fatty acid metabolism. Int J Biochem Cell Biol. 2017:84:40-5.

4. Panov A, Orynbayeva Z, Vavilin V, Lyakhovich V. Fatty acids in energy metabolism of the central nervous system. Biomed Res Int. 2014;2014:472459.

5. Cunnane SC, Trushina E, Morland C, Prigione A, Casadesus G, Andrews ZB, Beal MF, Bergersen LH, Brinton RD, de la Monte $S$, et al. Brain energy rescue: an emerging therapeutic concept for neurodegenerative disorders of ageing. Nat Rev Drug Discov. 2020;19:609-33.

6. Henderson ST, Vogel JL, Barr L, Garvin F, Jones JJ, Costantini LC. Study of the ketogenic agent AC-1202 in mild to moderate Alzheimer's disease: a randomized, double-blind, placebo-controlled, multicenter trial. Nutr Metab (Lond). 2009;6:31.

7. Fortier M, Castellano CA, Croteau E, Langlois F, Bocti C, St-Pierre V, Vandenberghe C, Bernier M, Roy M, Descoteaux M, et al. A ketogenic drink improves brain energy and some measures of cognition in mild cognitive impairment. Alzheimers Dement. 2019:15:625-34.

8. Croteau E, Castellano CA, Richard MA, Fortier M, Nugent S, Lepage M, Duchesne S, Whittingstall K, Turcotte ÉE, Bocti C, et al. Ketogenic medium chain triglycerides increase brain energy metabolism in Alzheimer's disease. J Alzheimers Dis. 2018;64:551-61.

9. Augustin K, Khabbush A, Williams S, Eaton S, Orford M, Cross JH, Heales SJR, Walker MC, Williams RSB. Mechanisms of action for the mediumchain triglyceride ketogenic diet in neurological and metabolic disorders. Lancet Neurol. 2018;17:84-93.

10. Borges K, Kaul N, Germaine J, Kwan P, O'Brien TJ. Randomized trial of addon triheptanoin vs medium chain triglycerides in adults with refractory epilepsy. Epilepsia Open. 2019;4:153-63.

11. Han FY, Conboy-Schmidt L, Rybachuk G, Volk HA, Zanghi B, Pan Y, Borges K. Dietary medium chain triglycerides for management of epilepsy: new data from human, dog, and rodent studies. Epilepsia. 2021;62:1790-1806.

12. Thavendiranathan P, Mendonca A, Dell C, Likhodii SS, Musa K, Iracleous C, Cunnane SC, Burnham WM. The MCT ketogenic diet: effects on animal seizure models. Exp Neurol. 2000;161:696-703.

13. Likhodii SS, Musa K, Mendonca A, Dell C, Burnham WM, Cunnane SC Dietary fat, ketosis, and seizure resistance in rats on the ketogenic diet. Epilepsia. 2000;41:1400-10.

14. Oldendorf WH. Carrier-mediated blood-brain barrier transport of shortchain monocarboxylic organic acids. Am J Physiol. 1973;224:1450-3.

15. Spector R. Fatty acid transport through the blood-brain barrier. J Neurochem. 1988:50:639-43.

16. Wlaź P, Socała K, Nieoczym D, Łuszczki JJ, Zarnowska I, Zarnowski T, Czuczwar SJ, Gasior M. Anticonvulsant profile of caprylic acid, a main constituent of the medium-chain triglyceride (MCT) ketogenic diet, in mice. Neuropharmacology. 2012;62:1882-9.

17. Wlaź P, Socała K, Nieoczym D, Żarnowski T, Żarnowska I, Czuczwar SJ, Gasior M. Acute anticonvulsant effects of capric acid in seizure tests in mice. Prog Neuropsychopharmacol Biol Psychiatry. 2015;57:110-6.

18. Barros LF, Brown A, Swanson RA. Glia in brain energy metabolism: a perspective. Glia. 2018;66:1134-7.

19. Schousboe A, Bak LK, Waagepetersen HS. Astrocytic control of biosynthesis and turnover of the neurotransmitters glutamate and GABA. Front Endocrinol (Lausanne). 2013;4:102.

20. Andersen JV, Markussen KH, Jakobsen E, Schousboe A, Waagepetersen HS, Rosenberg PA, Aldana BI. Glutamate metabolism and recycling at the excitatory synapse in health and neurodegeneration. Neuropharmacology. 2021;15:108719.

21. Bak LK, Schousboe A, Waagepetersen HS. The glutamate/GABA-glutamine cycle: aspects of transport, neurotransmitter homeostasis and ammonia transfer. J Neurochem. 2006;98:641-53.

22. Hertz L. The glutamate-glutamine (GABA) cycle: importance of late postnatal development and potential reciprocal interactions between biosynthesis and degradation. Front Endocrinol (Lausanne). 2013:4:59.

23. Eid T, Thomas MJ, Spencer DD, Rundén-Pran E, Lai JC, Malthankar GV, Kim JH, Danbolt NC, Ottersen OP, de Lanerolle NC. Loss of glutamine synthetase in the human epileptogenic hippocampus: possible mechanism for raised extracellular glutamate in mesial temporal lobe epilepsy. Lancet. 2004:363:28-37.
24. Eid T, Ghosh A, Wang Y, Beckström H, Zaveri HP, Lee TS, Lai JC, MalthankarPhatak GH, de Lanerolle NC. Recurrent seizures and brain pathology after inhibition of glutamine synthetase in the hippocampus in rats. Brain. 2008;131:2061-70.

25. Skotte NH, Andersen JV, Santos A, Aldana BI, Willert CW, Norremolle A, Waagepetersen HS, Nielsen ML. Integrative characterization of the R6/2 mouse model of Huntington's disease reveals dysfunctional astrocyte metabolism. Cell Rep. 2018;23:2211-24.

26. Norenberg MD, Martinez-Hernandez A. Fine structural localization of glutamine synthetase in astrocytes of rat brain. Brain Res. 1979;161:303-10.

27. McKenna MC. Glutamate pays its own way in astrocytes. Front Endocrinol (Lausanne). 2013:4:191.

28. Cremer JE, Teal HM, Heath DF, Cavanagh JB. The influence of portocaval anastomosis on the metabolism of labelled octanoate, butyrate and leucine in rat brain. J Neurochem. 1977;28:215-22.

29. Edmond J, Robbins RA, Bergstrom JD, Cole RA, de Vellis J. Capacity for substrate utilization in oxidative metabolism by neurons, astrocytes, and oligodendrocytes from developing brain in primary culture. J Neurosci Res. 1987;18:551-61.

30. Ebert D, Haller RG, Walton ME. Energy contribution of octanoate to intact rat brain metabolism measured by $13 \mathrm{C}$ nuclear magnetic resonance spectroscopy. J Neurosci. 2003;23:5928-35.

31. McNair LF, Kornfelt R, Walls AB, Andersen JV, Aldana BI, Nissen JD, Schousboe A, Waagepetersen HS. Metabolic characterization of acutely isolated hippocampal and cerebral cortical slices using [U-13C]glucose and [1,2-13C]acetate as substrates. Neurochem Res. 2017;42:810-26.

32. Tan KN, Carrasco-Pozo C, McDonald TS, Puchowicz M, Borges K. Tridecanoin is anticonvulsant, antioxidant, and improves mitochondrial function. J Cereb Blood Flow Metab. 2017;37:2035-48.

33. Nasrallah FA, Garner B, Ball GE, Rae C. Modulation of brain metabolism by very low concentrations of the commonly used drug delivery vehicle dimethyl sulfoxide (DMSO). J Neurosci Res. 2008:86:208-14.

34. Walls AB, Bak LK, Sonnewald U, Schousboe A, Waagepetersen HS. Metabolic mapping of astrocytes and neurons in culture using stable isotopes and gas chromatography-mass spectrometry (gc-ms). In brain energy metabolism neuromethods, vol 90. In: Hirrlinger J, Waagepetersen HS, eds. New York: Humana Press; 2014

35. Andersen JV, Christensen SK, Nissen JD, Waagepetersen HS. Improved cerebral energetics and ketone body metabolism in $\mathrm{db} / \mathrm{db}$ mice. J Cereb Blood Flow Metab. 2017;37:1137-47.

36. Andersen JV, Christensen SK, Aldana BI, Nissen JD, Tanila H, Waagepetersen HS. Alterations in cerebral cortical glucose and glutamine metabolism precedes amyloid plaques in the APPswe/PSEN1de9 mouse model of Alzheimer's disease. Neurochem Res. 2017:42:1589-98.

37. Andersen JV, Jakobsen E, Westi EW, Lie MEK, Voss CM, Aldana BI, Schousboe A, Wellendorph P, Bak LK, Pinborg LH, Waagepetersen HS. Extensive astrocyte metabolism of $\gamma$-aminobutyric acid (GABA) sustains glutamine synthesis in the mammalian cerebral cortex. Glia. 2020;68:2601-12.

38. Divakaruni AS, Brand MD. The regulation and physiology of mitochondria proton leak. Physiology (Bethesda). 2011;26:192-205.

39. Pan JW, de Graaf RA, Petersen KF, Shulman Gl, Hetherington HP, Rothman DL. [2,4-13 C2 ]-beta-hydroxybutyrate metabolism in human brain. J Cereb Blood Flow Metab. 2002;22:890-8.

40. Kamp F, Hamilton JA. How fatty acids of different chain length enter and leave cells by free diffusion. Prostaglandins Leukot Essent Fatty Acids. 2006;75:149-59.

41. Khabbush A, Orford M, Tsai YC, Rutherford T, O'Donnell M, Eaton S, Heales SJR. Neuronal decanoic acid oxidation is markedly lower than that of octanoic acid: a mechanistic insight into the medium-chain triglyceride ketogenic diet. Epilepsia. 2017;58:1423-9.

42. Jernberg JN, Bowman CE, Wolfgang MJ, Scafidi S. Developmental regulation and localization of carnitine palmitoyltransferases (CPTs) in rat brain. J Neurochem. 2017;142:407-19.

43. Andersen JV, McNair LF, Schousboe A, Waagepetersen HS. Specificity of exogenous acetate and glutamate as astrocyte substrates examined in acute brain slices from female mice using methionine sulfoximine (MSO) to inhibit glutamine synthesis. J Neurosci Res. 2017;95:2207-16.

44. Sonnewald U, Westergaard N, Schousboe A, Svendsen JS, Unsgard G, Petersen SB. Direct demonstration by [13C]NMR spectroscopy that glutamine from astrocytes is a precursor for GABA synthesis in neurons. Neurochem Int. 1993:22:19-29. 
45. Geyer RP, Matthews LW, Stare FJ. Metabolism of emulsified trilaurin (-C1400-) and octanoic acid (-C1400-) by rat tissue slices. J Biol Chem. 1949;180:1037-45.

46. Xicoy H, Wieringa B, Martens GJ. The SH-SY5Y cell line in Parkinson's disease research: a systematic review. Mol Neurodegener. 2017;12:10

47. Longo N, Frigeni M, Pasquali M. Carnitine transport and fatty acid oxidation. Biochim Biophys Acta. 2016;1863:2422-35.

48. Nandy A, Kieweg V, Kräutle FG, Vock P, Küchler B, Bross P, Kim JJ, Rasched I, Ghisla S. Medium-long-chain chimeric human Acyl-CoA dehydrogenase: medium-chain enzyme with the active center base arrangement of longchain Acyl-CoA dehydrogenase. Biochemistry. 1996;35:12402-11.

49. Haynes VR, Michael NJ, van den Top M, Zhao FY, Brown RD, De Souza D, Dodd GT, Spanswick D, Watt MJ. A Neural basis for Octanoic acid regulation of energy balance. Mol Metab. 2020;34:54-71.

50. Thevenet J, De Marchi U, Domingo JS, Christinat N, Bultot L, Lefebvre G, Sakamoto K, Descombes P, Masoodi M, Wiederkehr A. Medium-chain fatty acids inhibit mitochondrial metabolism in astrocytes promoting astrocyte-neuron lactate and ketone body shuttle systems. Faseb j. 2016;30:1913-26.

51. Brookes PS. Mitochondrial $\mathrm{H}(+)$ leak and ROS generation: an odd couple. Free Radic Biol Med. 2005;38:12-23.

52. Hughes SD, Kanabus M, Anderson G, Hargreaves IP, Rutherford T, O'Donnell M, Cross JH, Rahman S, Eaton S, Heales SJ. The ketogenic diet component decanoic acid increases mitochondrial citrate synthase and complex I activity in neuronal cells. J Neurochem. 2014;129:426-33.

53. Sonnay S, Chakrabarti A, Thevenet J, Wiederkehr A, Christinat N, Masoodi M. Differential metabolism of medium-chain fatty acids in differentiated human-induced pluripotent stem cell-derived astrocytes. Front Physiol. 2019;10:657.

54. Malapaka RR, Khoo S, Zhang J, Choi JH, Zhou XE, Xu Y, Gong Y, Li J, Yong EL, Chalmers MJ, et al. Identification and mechanism of 10-carbon fatty acid as modulating ligand of peroxisome proliferator-activated receptors. J Biol Chem. 2012;287:183-95.

55. Miglio G, Rosa AC, Rattazzi L, Collino M, Lombardi G, Fantozzi R. PPARgamma stimulation promotes mitochondrial biogenesis and prevents glucose deprivation-induced neuronal cell loss. Neurochem Int 2009;55:496-504.

56. loannou MS, Jackson J, Sheu SH, Chang CL, Weigel AV, Liu H, Pasolli HA, Xu CS, Pang S, Matthies D, et al. Neuron-astrocyte metabolic coupling protects against activity-induced fatty acid toxicity. Cell. 2019;177:15221535.e1514.
57. Qi G, Mi Y, Shi X, Gu H, Brinton RD, Yin F. ApoE4 impairs neuron-astrocyte coupling of fatty acid metabolism. Cell Rep. 2021;34:108572.

58. Damiano F, De Benedetto GE, Longo S, Giannotti L, Fico D, Siculella L, Giudetti AM. Decanoic acid and not octanoic acid stimulates fatty acid synthesis in U87MG glioblastoma cells: a metabolomics study. Front Neurosci. 2020;14:783.

59. Lee N, Sa M, Hong YR, Lee CJ, Koo J. Fatty acid increases CAMP-dependent lactate and MAO-B-dependent GABA production in mouse astrocytes by activating a $\mathrm{G}(\mathrm{as})$ protein-coupled receptor. Exp Neurobiol. 2018;27:365-76.

60. Andersen JV, Christensen SK, Westi EW, Diaz-delCastillo M, Tanila H, Schousboe A, Aldana BI, Waagepetersen HS. Deficient astrocyte metabolism impairs glutamine synthesis and neurotransmitter homeostasis in a mouse model of Alzheimer's disease. Neurobiol Dis. 2021;148:105198.

61. Yoon BE, Woo J, Chun YE, Chun H, Jo S, Bae JY, An H, Min JO, Oh SJ, Han KS, et al. Glial GABA, synthesized by monoamine oxidase B, mediates tonic inhibition. J Physiol. 2014;592:4951-68.

62. Kwak H, Koh W, Kim S, Song K, Shin Jl, Lee JM, Lee EH, Bae JY, Ha GE, Oh JE, et al. Astrocytes control sensory acuity via tonic inhibition in the thalamus. Neuron. 2020;108:691-706.e610.

63. Page KA, Williamson A, Yu N, McNay EC, Dzuira J, McCrimmon RJ, Sherwin RS. Medium-chain fatty acids improve cognitive function in intensively treated type 1 diabetic patients and support in vitro synaptic transmission during acute hypoglycemia. Diabetes. 2009;58:1237-44.

64. Warren EC, Dooves S, Lugarà E, Damstra-Oddy J, Schaf J, Heine VM, Walker MC, Williams RSB. Decanoic acid inhibits mTORC 1 activity independent of glucose and insulin signaling. Proc Natl Acad Sci U S A. 2020;117:23617-25.

65. Chang P, Augustin K, Boddum K, Williams S, Sun M, Terschak JA, Hardege JD, Chen PE, Walker MC, Williams RS. Seizure control by decanoic acid through direct AMPA receptor inhibition. Brain. 2016;139:431-43.

66. Bennett ML, Viaene AN. What are activated and reactive glia and what is their role in neurodegeneration? Neurobiol Dis. 2021;148:105172.

\section{Publisher's Note}

Springer Nature remains neutral with regard to jurisdictional claims in published maps and institutional affiliations.
Ready to submit your research? Choose BMC and benefit from:

- fast, convenient online submission

- thorough peer review by experienced researchers in your field

- rapid publication on acceptance

- support for research data, including large and complex data types

- gold Open Access which fosters wider collaboration and increased citations

- maximum visibility for your research: over $100 \mathrm{M}$ website views per year

At BMC, research is always in progress.

Learn more biomedcentral.com/submissions 